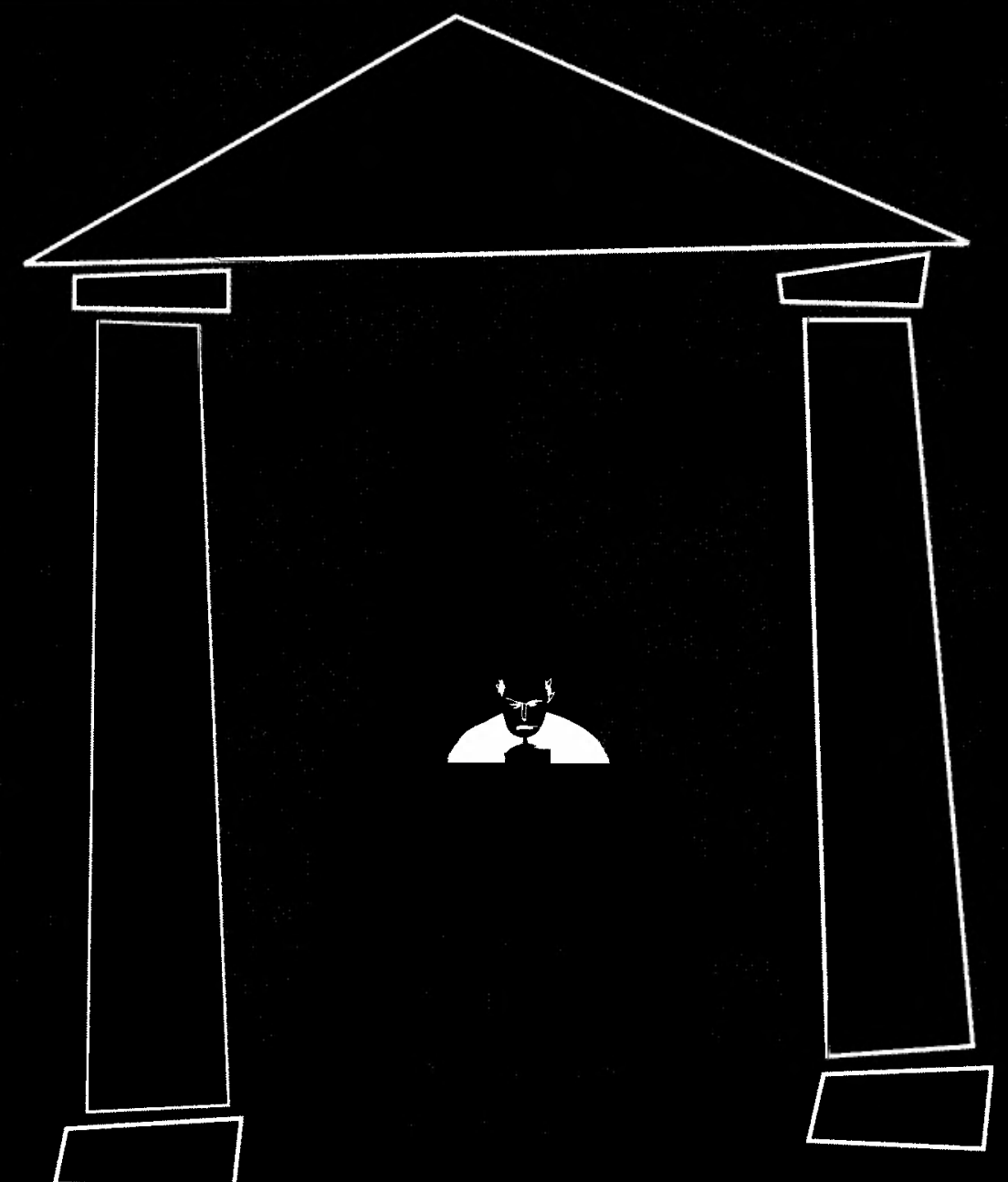

\title{
ORGANIZAÇÕES COMO CONFIGURAÇÕES NATURAIS DO PODER
}

\section{Primo Falcini}

Mestre e Doutorando em Administração de Empresas pela EAESP/FGV e Consultor de Empresas.

* RESUM0: O propósito deste artigo é examinar as idéias de Henry Mintzberg sobre as configurações do poder que permeiam as organizações. São analisadas as premissas e hipóteses de sua teoria descritiva e as características gerais dos respectivos "tipos genuinos" de organizações que correspondem às configurações tidas como naturais.
* PALAVRAS-CHAVE: Poder, organizações, configurações naturais, coalizões internas, coalizões externas.

* ABSTRACT: The basic aim of this article is to review Henry Mintzberg's ideas about the power configurations permeated through organizations. The assumptions and hypotheses of his descriptive theory are introduced, as well as the general characteristics of the corresponding "genuine types" organizations, described as the natural configurations of power.

* KEY WORDS: Power, organizations, natural configurations, internal coalition, external coalition.

São Paulo, 33(1):6-15

Jan./Fev. 1993 


\section{INTRODUÇÃO}

O poder, aqui entendido simplesmente como uma força capaz de influenciar decisivamente os resultados operacionais das organizações, é um elemento-chave e de extrema importância para a compreensão dos comportamentos organizacionais.

O Prof. Dr. Henry Mintzberg ${ }^{1}$ percebendo a importância desse fator, oferece uma excelente contribuição para a formação de um paradigma sobre essa área da realidade que explora.

Partindo da explicação dos elementos básicos que participam do jogo do poder organizacional, aos quais chama de "influenciadores", analisa os meios e sistemas de influência que utilizam e verifica quais os sistemas de metas organizacionais resultantes.

Compondo esses elementos entre si, oferece uma interessante teoria descritiva sobre as configurações do poder nas organizações.

Considerando a importância desse assunto e a qualidade desse trabalho, este artigo visa a examinar essa teoria com o objetivo de renovar os interesses acadêmicos e profissionais num melhor entendimento dos fenômenos comportamentais relacionados ao poder nas organizações.

A primeira parte deste estudo resume algumas das tipologias mais conhecidas, isoladas por aquele autor, no campo do poder organizacional.

Na sequiência, são demonstradas as bases em que se apóia a teoria de Mintzberg, que trata das relações entre as coalizões de poder, com as consequientes configurações organizacionais, onde se destacam as premissas e hipóteses adotadas.

A terceira parte sintetiza as combinações gerais decorrentes das coalizões, com ênfase àquelas configurações tidas como naturais, e a última parte consolida as conclusões gerais deste estudo.

\section{TIPOLOGIAS ORGANIZACIONAIS COM BASE NO PODER}

Como uma síntese do estado do conhecimento neste campo, destacam-se entre as mais conhecidas as teorias de Etzioni $^{2}$, Blau e Scott ${ }^{3}$ e de Rhenman. ${ }^{4}$ Cada uma delas vê o foco do poder fixado ou nas características internas da organização, ou nas suas características externas, ou em ambas.

\section{Foco na estrutura interna}

Etzioni construiu sua tipologia organizacional exclusivamente com base nas características internas das organizações,

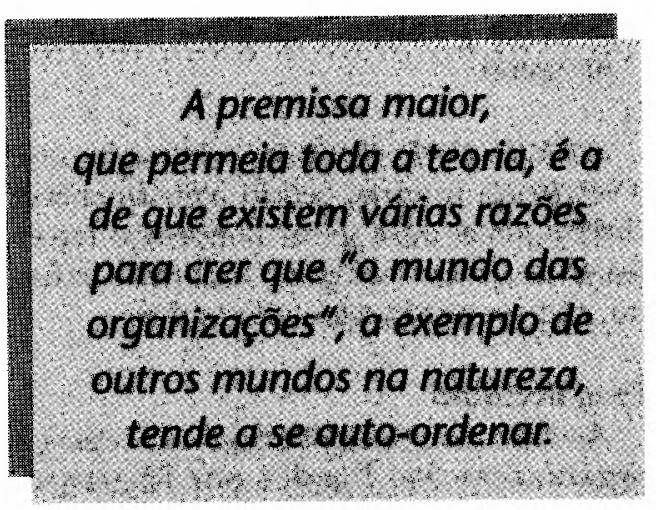

classificando-as através dos meios de controle utilizados para se obterem um comportamento desejado de seus participantes internos e correspondente nível de envolvimento para com as mesmas.

Nessa linha, propôs três tipos básicos de organizações:

- Coercitiva: onde os meios de controle são "coercitivos" e o envolvimento dos participantes internos é "alienativo".

- Utilitária: os meios de controle "são "remunerativos" e o envolvimento daqueles participantes é "calculativo".

- Normativa: com meios de controle "normativos" e envolvimento "moral" dos participantes internos.

Apesar de possuir uma única dimensão de poder, já que se centra apenas na parte interna, ou estrutura, da organização, esta teoria é bastante útil pois que se baseia em comportamentos reais.

\section{Foco no meio ambiente}

Blau e Scott, por sua vez, centraram sua teoria nas características externas das organizações, decorrentes de seus meios ambientes, categorizando-as em função de seus "beneficiários principais", ou seja, aqueles para cujo benefício as organizações são criadas.

Propõem quatro tipos de organizações,
1. MINTZBERG, H. Power in and around organizations. Englewood Cliffs, N.J, Prentice Hall, 1983.

2. ETZIONI, A. A Comparative analysis of complex organizations. New York, Free Press, 1961.

3. BLAU P.M. \& SCOTT, W. R. Formal organizations : a comparative approach. San Francisco, Chandler, 1962.

4. RHENMAN, E. Organization theory for long-range planning. New York, John Willey, 1973. 
5. HIRSCHMAN, A. O. Exit, voice and loyalty: responses to decline in firms, organizations and states. Cambridge, Mass., Harvard University Press, 1970.

6. ALLISON, G. T. Essence of decision: explaining the cuban missile crises. Boston, Little Brown, 1971.

7. A palavra "influência" e derivadas são entendidas, neste artigo, como um sinônimo de poder. "Influência" é o poder afetando os demais: influenciadores são os detentores do poder. que, na realidade, correspondem a quatro tipos de beneficiários:

- Interesses de negócios: cujos beneficiários principais são os seus proprietários.

- Serviços: onde os clientes são os beneficiários principais.

- Benefício mútuo: que beneficia principalmente seus membros participantes.

- Serviço público: beneficia o público em geral.

Através desta tipologia, deduz-se que a estrutura interna, sendo instrumentalizada apenas para gerar benefícios àqueles situados em seu meio ambiente externo, não possuiria o foco do poder.

\section{Foco dividido}

As características internas e externas à organização são ligadas por Rhenman, derivando daí quatro tipologias:

- Marginais: correspondendo àquelas organizações sem qualquer foco estratégico interno, nem qualquer missão externa; suas mudanças estratégicas são oportunistas ou reativas.

- Corporações: com foco estratégico interno, mas sem qualquer missão imposta de fora para dentro da organização.

- Acessórias: que operam exclusivamente em função de interesses específicos externos dos quais dependerão para sua própria sobrevivência.

- Instituições: com foco estratégico interno e missão imposta de fora, que poderão ou não se corresponderem.

Nos primeiros três tipos, o poder interno é mais ou menos centralizado; já no quarto tipo, tem-se o poder dividido entre alianças internas e externas à organização.

\section{OUTRAS TIPOLOGIAS}

Além desses trabalhos, dois outros devem ser mencionados pelas suas importâncias neste campo de pesquisa.

$\mathrm{O}$ primeiro desenvolvido por Hirschman ${ }^{5}$, que criou uma matriz de tipos organizacionais com base no fato de os membros da organização usarem ou não "a voz" (a luta), ou "a retirada" (a fuga), para expressarem seus descontentamentos.

O outro, desenvolvido por Allison ${ }^{6}$, que distingue três tipos de organizações:

- Ator nacional: onde a organização é vista atuando de um modo útil como uma entidade simples e unificada.

- Processo organizacional: no qual as ações organizacionais são designadas para a interação de um amplo repertório de programas padronizados.

- Políticas governamentais: as ações organizacionais são vistas como resultantes de vários jogos políticos e acordos entre os diferentes atores.

Pode-se observar que todas essas teorias se limitam a explorar poucas dimensões do poder organizacional, o que vai inspirar Mintzberg no desenvolvimento de sua teoria.

\section{A TEORIA DE MINTZBERG}

É, pois, a tentativa de localizar um maior número de dimensões do poder organizacional, ao invés de relacionar algumas poucas, que vai diferenciar a teoria de Mintzberg em relação à maioria das acima citadas.

Em um aspecto, porém, sua teoria vai se aproximar de Rhenman, pois que, a exemplo deste, propõe que as tipologias das configurações de poder derivam da relação entre as coalizões externas e internas de poder.

O enfoque desta teoria é demonstrar como os influenciadores externos e internos $^{7}$ atuam nas respectivas coalizões, os meios e os sistemas de influência que utilizam, os tipos de alianças internas e externas que formam e os sistemas de metas resultantes, cujas combinações, feitas de várias maneiras, vão gerar as configurações do poder organizacional.

A premissa maior, que permeia toda a teoria, é a de que existem várias razões para crer que "o mundo das organizações", a exemplo de outros mundos na natureza, tende a se auto-ordenar, de modo "natural", em grupos específicos com caracteristícas comuns, revelando assim uma certa dose de determinismo.

Assim, as organizações tenderiam a se 
concentrar em torno desses grupos no sentido de obter consistência nas suas características, sinergia nos seus processos e harmonia nas suas situações.

Essas "forças naturais de seleção" agiriam a favor das organizações, tornandoas capazes de desenvolver complementaridades mútuas entre os seus elementos.

Seguindo essa ordem de idéias, das combinaçōes infinitas de poder, que seriam possíveis em teoria, poucas combinações ocorrentes na realidade seriam suficientes para explicar o comportamento relacionado ao poder, interno e externo, nas organizações.

Esses poucos conjuntos são classificados como "tipos genuínos", e não tipos ideais, pois que não descrevem com precisão a realidade, mas muito mais refletem as "tendências" que ocorrem na realidade.

Partindo, pois, desta premissa básica que um conjunto de "tipos genuínos" de configurações de poder pode explicar, em boa medida, o comportamento relativo ao poder organizacional, o passo seguinte é deduzir tal conjunto de modo sistemático.

Esse "tipo genuíno" de organização, cabe aqui destacar, é uma caricatura da realidade, uma espécie de exagero do que poderia ocovrer no mundo real.

Tal "tipo" é criado propositalmente, justamente para que certas de suas características sejam evidenciadas.

A adoção do mesmo exige premissas, que são fixadas como princípios, visando a simplificar a realidade:

\section{Princípios}

1․ Algumas das várias coalizões internas e externas se ajustam mais naturalmente.

$2^{2}$ A coalizăo interna estará em seu estado mais natural, quando dominada por apenas um de seus sistemas de influência, (controle pessoal, burocrático, ideológico, por especialista ou político), que agem em conjunto e se interrelacionam nas fases temporais da organização.

$3^{\circ}$ A palavra "natural" significa que existem certas forças inerentes à organização que dirigem seu comportamento de determinadas maneiras.

Na sequiência, são dispostas as quatro hipóteses que norteiam a formaçăo dedutiva dos "tipos genuínos" (modelos) de organizaçōes que decorrem da relação entre as coalizões internas e externas de poder.

As três primeiras hipóteses deduzem as combinações mais naturais entre as coalizöes externa e interna de poder, presumindo a dominância de uma delas.

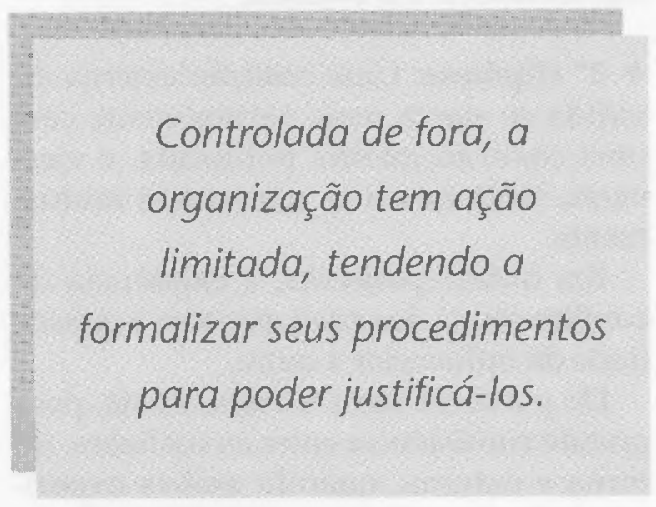

A quarta hipótese deduz o que acontece quando outras combinações ocorrem entre as duas formas de coalizões de poder.

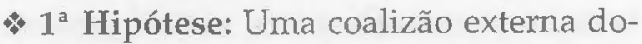
mina-se por um ou mais influenciadores externos, ajusta-se mais naturalmente com uma coalizão interna burocrática, tendendo a reforçá-la.

A dominação exercida sobre a coalizão externa significa que um dado influenciador externo, ou um grupo deles, agindo em conjunto, e possuindo o controle de qualquer tipo de dependência organizacional, terá um poder decisivo sobre toda a organização, quando comparado com os demais participantes externos ou internos.

Essa concentração de poder faz com que os elementos internos à organização acabem se submetendo às demandas do influenciador externo dominante, o qual desenvolverá todos os meios para, de fora, controlar a organização.

Dessa forma, tal influenciador externo nomeia o executivo principal de sua confiança, fazendo-o responsável pelas ações e performnnces organizacionais, de forma a fortalecer o sistema de autoridade $e$ centralizar todo o poder.

$\mathrm{O}$ influenciador externo impõe, sobre 
8. Metas são as intenções ou propósitos dirigindo as decisões ou açôes. Objetivos sāo metas expressas de forma que seus resultados possam ser medidos. esse executivo principal, as metas operacionais, que as formaliza num sistema de metas e objetivos. $\$$

Controlada de fora, a organização tem ação limitada, tendendo a formalizar seus procedimentos para poder justificálos. O resultado fatal é que a dominação externa gera a centralização com conseqüente formalização, o que torna a coalizão interna, na estrutura organizacional, extremamente burocrática.

* 2n Hipótese: Uma coalizão externa dividida se ajusta mais naturalmente com uma coalizão interna politizada, e viceversa, tendendo a se reforçarem mutuamente.

Em outras palavras, a existência do conflito numa das coalizōes tem a capacidade de influenciar a outra.

Do ponto de vista natural, existe, pois, grande consistência entre as coalizōes, interna e externa, quando ambas experimentam o conflito em seus interiores, o que gera um estado de estabilidade maior do que quando somente uma delas o experimenta.

- $3^{a}$ Hipótese: As coalizões internas nas formas personalizadas, ideológica ou profissional-especializada, ajustam-se mais naturalmente com uma coalizão externa passiva; uma coalizão interna burocrática pode, também, a esta última, ajustar-se; todos esses quatro tipos de coalizão interna tenderão a reforçar a coalizão

\section{Combinações naturais} entre as coalizões

\section{Quadro 1:}

\begin{tabular}{|c|c|c|}
\hline COALIZÃO & COALIZ̃̃̃ & CONF. PODER ORGAN. \\
\hline EXTERNA & INTERNA & \\
\hline Ativa-dominada ${ }^{*}$ & Burocrática & Instrumento \\
\hline Passiva & Burocrática* & Sistema Fechado \\
\hline Passiva. & Personalizada ${ }^{*}$ & Autocracia \\
\hline Passiva & Ideológica* & Missionária \\
\hline Passiva & Profissional ${ }^{*}$ & Meritocraçia \\
\hline Dividida & Politizada & Arena Política \\
\hline
\end{tabular}

externa passiva.

$\mathrm{Na}$ verdade, esta hipótese complementa as duas anteriores, já que representa, por assim dizer, o saldo das possiblidades das relações entre as coalizöes, tidas como naturais.

$\mathrm{O}$ vácuo de poder criado pela passividade na coalizão externa será absorvido naturalmente por algum foco de poder concentrado na coalizão interna. Aliás, a única maneira de se assegurar que o poder na coalizão externa continue passivo é mantê-lo claramente focado em alguma das formas de coalizão interna.

Através destas três hipóteses já se podem deduzir as seis combinaçōes mais naturais entre as coalizões interna e externa, as quais são resumidas no quadro 1 .

* $4^{\mathrm{a}}$ Hipótese: Quaisquer outras combinaçōes de coalizões internas e externas, ou de sistemas interiores de influência em cada uma, geram, freqüientemente, níveis, de moderados a intensos, de conflito.

Em última análise, esta hipótese reza que a violação de uma das três hipóteses anteriores vai provocar níveis significantes de conflito.

A tentativa de operar com uma combinação menos natural de poder terá o efeito de politizar a coalizão interna e/ou dividir a coalizăo externa, deduzindo-se que uma combinação natural entre as coalizōes emergirá tão somente quando existir um foco centralizado de poder; de outro modo, o conflito é que será natural.

Destarte, as nove combinações restantes possíveis tendem, pela sua natureza, a gerar graus variáveis de conflitos entre as coalizões, ou mesmo internamente a cada uma delas.

Por outro lado, apesar de essas combinações restantes serem menos naturais, e portanto, menos consistentes e harmônicas, e, provavelmente menos estáveis e comuns que as demais, năo devem ser consideradas como aberraçōes disfuncionais.

$\mathrm{Na}$ realidade, são também funcionais se consideradas como ocorrentes em fases litigiosas e conflitantes da luta pelo poder, quando serão necessárias para a consecução da transição de uma para outra configuração mais natural.

Como resultado final dessas quatro hi- 


\section{Quadro 2 Combinações gerais entre as coalizões}

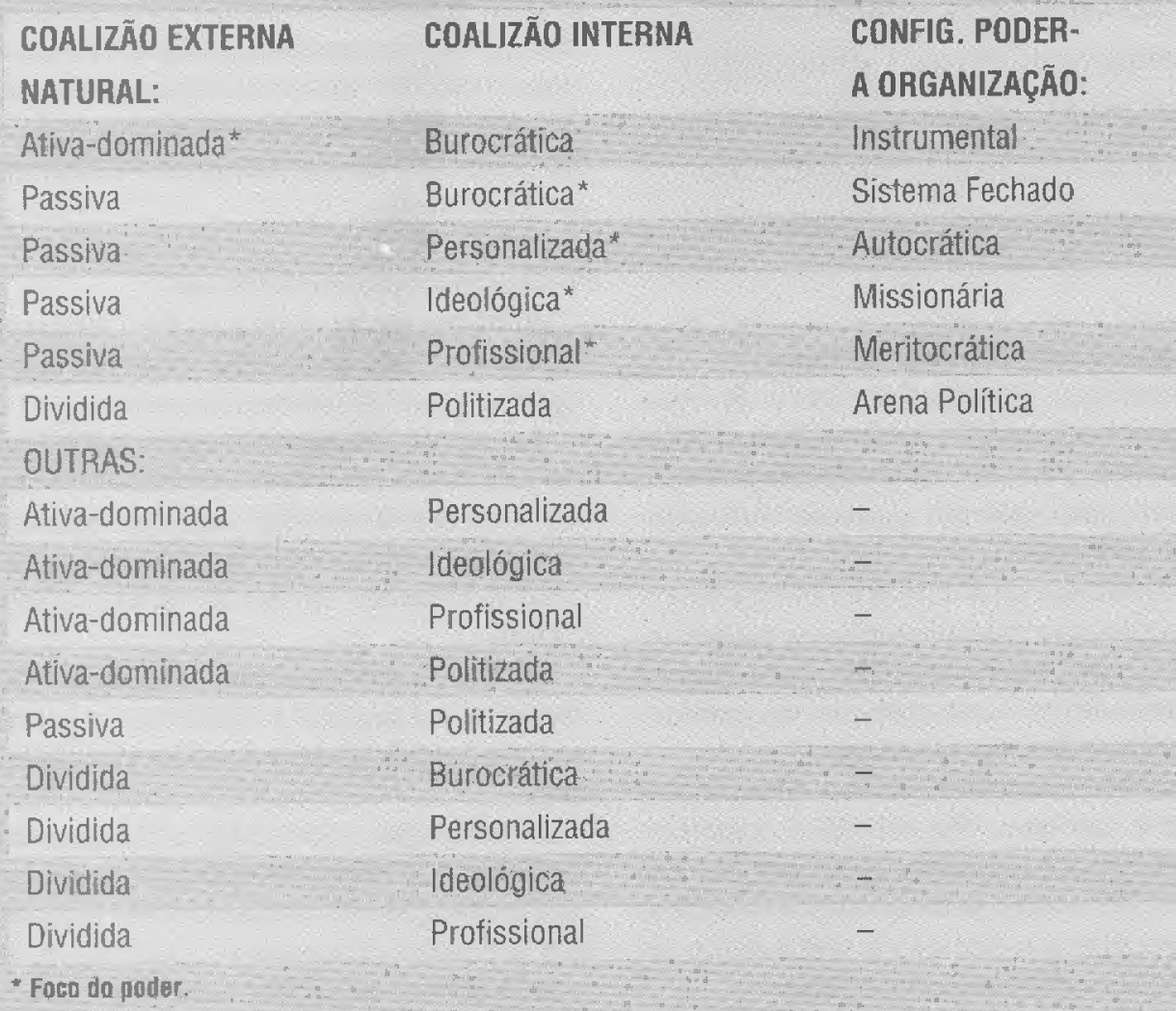

póteses, o quadro 2 sintetiza todas as combinações possíveis:

As nove combinaçóes mencionadas no quadro 2 como "outras", sāo provavelmente menos comuns e estáveis, tendendo a se transformar numa configuração do tipo arena política. Podem, às vezes, operar de forma híbrida, através de acordos instáveis entre os detentores do poder, ou durante o tempo necessário de transição para uma das formas classificadas como naturais.

\section{CARACTERÍSTICAS DAS CONFIGURAÇÕES NATURAIS DO PODER}

A seguir, é apresentada uma síntese das características gerais relativas às seis configurações naturais do poder.

\section{1- Organização instrumental}

Este tipo de organização serve aos desígnios de um influencjador externo do- minante, ou a um grupo deles agindo consensualmente.

A coalizăo interna é burocratizada, visto que o controle externo a uma organização funciona mais eficientemente através da utilização de controles burocráticos; assim, a coalizão interna é disposta para perseguir e maximizar metas e objetivos exclusivamente operacionais que são impostos pelos influenciadores externos dominantes.

Os participantes internos são persuadidos a contribuir com seus esforços principalmente através de incentivos materiais e têm poucas oportunidades de realmente exercer o poder.

Esta configuração tende a aparecer especialmente quando uma organização tem uma dependência estratégica crítica do seu meio ambiente, incluindo-se disposições legais, ambas utilizadas por influenciadores externos com metas operacionais muito bem definidas. 
9. A missão descreve as funçōes básicas da organização junto à sociedade, em termos de produtos e serviços aos seus clientes.
A lealdade para com a organização não é forte; tais profissionais tendem a ser mais leais às suas associações profissionais, visto que a socialização é parte básica de suas formações profissionais.

\section{2- Organização sistema fechado}

Neste caso, quem vai se servir da organização é a coalizão interna burocrática, utilizando, para tal, os controles internos que são baseados em padrões burocráticos de trabalho.

A diferença aqui é que este tipo de organização não possui qualquer poder focado no seu meio ambiente, pois que os influenciadores externos se encontram dispersos e desorganizados.

Os administradores-chave absorvem o poder e também vão dirigir a organizaçăo através de um sistema de metas e objetivos. As metas perseguidas, em ordem de importância, são as de sobrevivência, eficiência, controle e crescimento.

Como é independente do controle externo, a organização aparelha-se para tentar controlar seu meio ambiente, de forma a servir a si mesma. Visto que é controlada internamente, tem mais espaço para jogos políticos do que a organização instrumental.

Esse tipo de configuração tende a aparecer nas grandes organizações, com certa tradição, com operações não especializadas, do tipo produção em massa, em meios ambientes estáveis onde seus influenciadores externos se encontrem dispersos.

\section{3- Organização autocrática}

Aqui, a coalizão externa é passiva; o poder é focado no executivo principal atuante na coalizão interna, o qual controla e dirige através de meios e qualidades pessoais.

Isso significa uma ausência virtual de jogos políticos, pois que os demais atores internos devem expressar lealdade ao "chefe" ou deixar a organização.

A organização normalmente persegue e maximiza aquelas metas que são definidas pelo executivo principal. Tem maior facilidade de se desenvolver em organizações pequenas e não transparentes, onde um simples indivíduo tem condições de manter um controle pessoal, naquelas operando em meios ambientes dinâmicos, naquelas com líderes fortes e determinados, ou ainda, naquelas enfrentando crises severas.

\section{4- Organização missionária}

A dominação, neste tipo, é efetuada através de uma ideologia, como forma de manter a coalizão externa passiva.

Ao invés de experimentar influência do seu meio ambiente, tenta, ao contrário, impor sua missão ${ }^{9}$ àquele; uma forte ideologia serve também para integrar a coalizão interna em torno de metas ideológicas.

Todos os esforços são dirigidos a perseguir e maximizar o objetivo de preservar ou aperfeiçoar a missão da organização.

A condição ideal para o surgimento deste tipo de configuração ocorre quando a organização foi conduzida, no passado, por um líder carismático, junto, às vezes, com a fama adquirida pela organização, situação essa que tende a gerar o desenvolvimento de fortes tradições em torno de uma missão clara, que agrega seus membros em torno dela.

\section{5- Organização meritocrática}

O poder aqui é focado internamente, especificamente sobre seus profissionais especialistas; a coalizão interna é do tipo profissional, se bem que a presença de especialistas, em vários campos de conhecimento, per si, significa algum nível de atividade política.

Os especialistas, pela sua natureza, lidam bem com a maioria das pressões oriundas da coalizão externa, mantendoa passiva.

A integração dos esforços dos especialistas desenvolve-se através de seus talentos e conhecimentos específicos, desenvolvidos em cursos e programas de desenvolvimento que precedem seus trabalhos, que os tornam bastante flexíveis para trocar de organização.

A lealdade para com a organização não é forte; tais profissionais tendem a 


\section{Características das configurações naturais do poder arganizacional}

\begin{tabular}{|c|c|c|c|c|c|c|}
\hline CARACTEAISTHCA: & Instrumental & Slstema Fechado. & Alllocrátitiza & Missionária " & Meriloterâtita & Arena Polltica \\
\hline Coalízăo Externg & Gtiva-dominada & Passiva & Passiva & Passiva & Passiva & Dividida \\
\hline Coalizăo Interna & Bufoeratica & Butocrátlca. & Personalizada. & If́eq|ẹglcz. & Profíssional & Polntizada \\
\hline $\begin{array}{l}\text { tnfluenciatores } \\
\text { principais }\end{array}$ & $\begin{array}{l}\text { Externo } \\
\text { domiaante }\end{array}$ & $\begin{array}{l}\text { Administradores } \\
\text { chaves }\end{array}$ & $\begin{array}{l}\text { Executivo } \\
\text { principal }\end{array}$ & $\begin{array}{l}\text { Tedos adiministradores } \\
\text { internos }\end{array}$ & $\begin{array}{l}\text { Especialistas } \\
\text { infernos }\end{array}$ & \\
\hline $\begin{array}{l}\text { Fluxo de poder } \\
\text { entro coalizoes }\end{array}$ & $\begin{array}{l}\text { Da coaluzio extema } \\
\text { parz a coalizăo interáa }\end{array}$ & $\begin{array}{l}\text { Nenhum ou da coalizäo } \\
\text { interna para a externa }\end{array}$ & 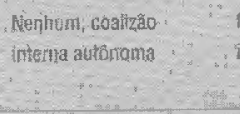 & $\begin{array}{l}\text { Nenhuma od da coalizão } \\
\text { interna para gexlema. }\end{array}$ & $\begin{array}{l}\text { En ambas direçōes; } \\
\text { coatizāo intorta } \\
\text { quase autơrioma }\end{array}$ & $\begin{array}{l}\text { Em ambas drectes; } \\
\text { as duas podem estar } \\
\text { em con }\end{array}$ \\
\hline Lberdade de açăd & $\begin{array}{l}\text { Metia a pecuenas escolha } \\
\text { dos molas para atingir fins } \\
\text { determinados }\end{array}$ & 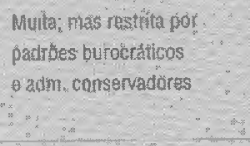 & $\begin{array}{l}\text { Mutta, roas restrita } \\
\text { pelo cresemento } \\
\text { y instabilidado } \\
\text { a }\end{array}$ & $\begin{array}{l}\text { Nivita en teura, } \\
\text { paquena na prátca } \\
\text { devido restrlyobs } \\
\text { nomás e trad. }\end{array}$ & 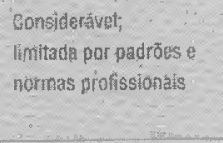 & $\begin{array}{l}\text { Pequent, orgatilizacáo } \\
\text { intuenciadores } \\
\text { dominados pelo conflito }\end{array}$ \\
\hline $\begin{array}{l}\text { Integração dos } \\
\text { ałares intemos }\end{array}$ & Peta persuasăo & Pela perblasão & Petă persuasão & $\begin{array}{l}\text { Por metas comuns } \\
\text { sccializaçăo o } \\
\text { doutrinaçăa }\end{array}$ & Por metas comuns & Pela nẹgociação \\
\hline $\begin{array}{l}\text { Identiticaęầo dos } \\
\text { atores Internos }\end{array}$ & Minima & Calculada & $\begin{array}{l}\text { Calculadar as : } \\
\text { vezes, natural }\end{array}$ & $\begin{array}{l}\text { Natural escoinida: } \\
\text { Evooada }\end{array}$ & $\begin{array}{l}\text { Evociada es escohida em } \\
\text { funçẫo da profissāa }\end{array}$ & 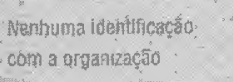 \\
\hline Helas lavoredidas & Operacionais pem definidas & $\begin{array}{l}\text { Sistema de meras; coim } \\
\text { ônfase an crescimento }\end{array}$ & $\begin{array}{l}\text { Pessoals; às vezes poude } \\
\text { incluir mişẫo e } \\
\text { sobrevivénga }\end{array}$ & 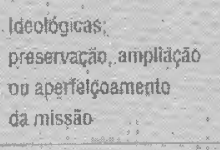 & $\begin{array}{l}\text { Missão, atitonomia } \\
\text { profissional e } \\
\text { exceletencia }\end{array}$ & Pessaais em geral \\
\hline Sistema de metas & Pode ser maximizaçâa & Maximuzaça & Pode ser maximizaçà & Maximizaça & $\begin{array}{l}\text { Atençäo seqiencaíl para } \\
\text { poutas melas basicas }\end{array}$ & 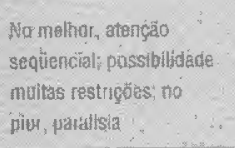 \\
\hline 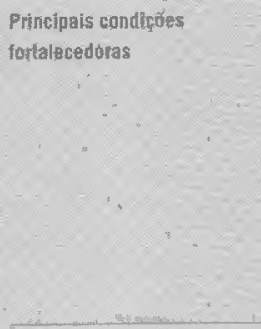 & 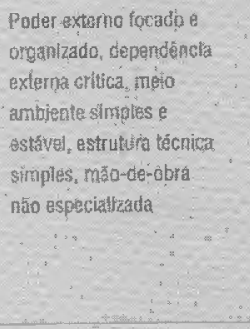 & 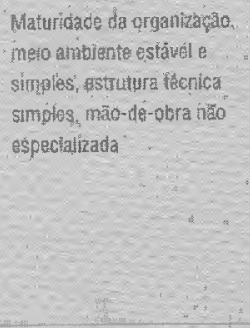 & 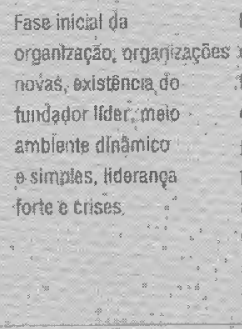 & 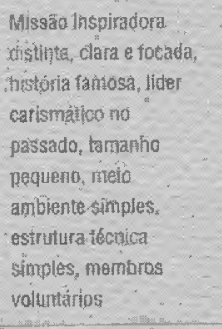 & $\begin{array}{l}\text { Tecnologia ou estrutura } \\
\text { tecrica complexa }\end{array}$ & 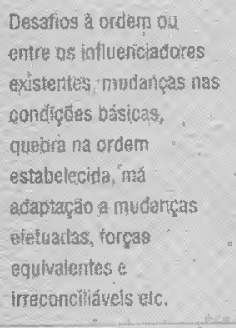 \\
\hline $\begin{array}{l}\text { Printipats condipäes } \\
\text { entraquegedoras }\end{array}$ & 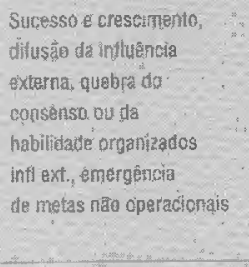 & 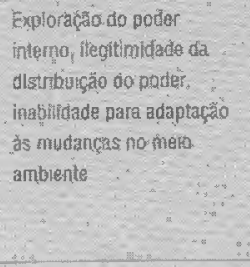 & 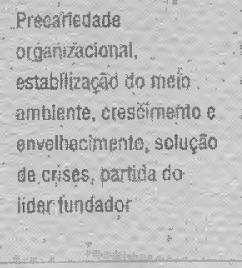 & 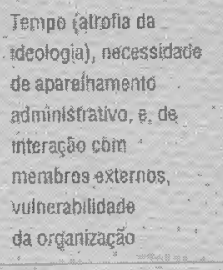 & 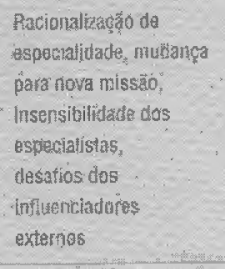 & 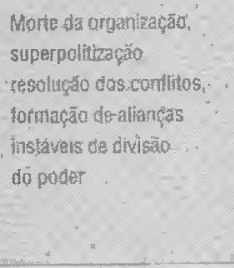 \\
\hline $\begin{array}{l}\text { Estáplo de desenwnlvimento } \\
\text { organizacional }\end{array}$ & $\begin{array}{l}\text { Eim Gesenwolvimento } \\
\text { para a maturidade }\end{array}$ & Maturidade & 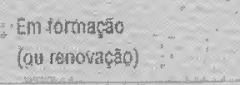 & $\begin{array}{l}\text { En desenvaivimento } \\
\text { ou lì na maturidade }\end{array}$ & 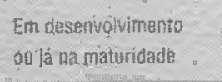 & $\begin{array}{l}\text { Beclinio e vansiçós. } \\
\text { entre outros estágies }\end{array}$ \\
\hline Equulvale no governo a: & $\begin{array}{l}\text { Colinnia também gaverno } \\
\text { elelto por olafo consenso. }\end{array}$ & 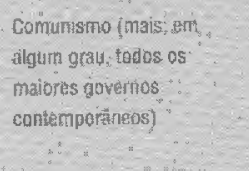 & $\begin{array}{l}\text { Ditadura fou lider } \\
\text { dithtorial numa } \\
\text { democracia) }\end{array}$ & Revoluçào cuitural & Męritootraelá & 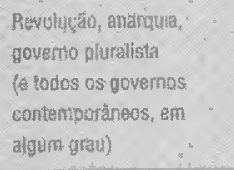 \\
\hline
\end{tabular}




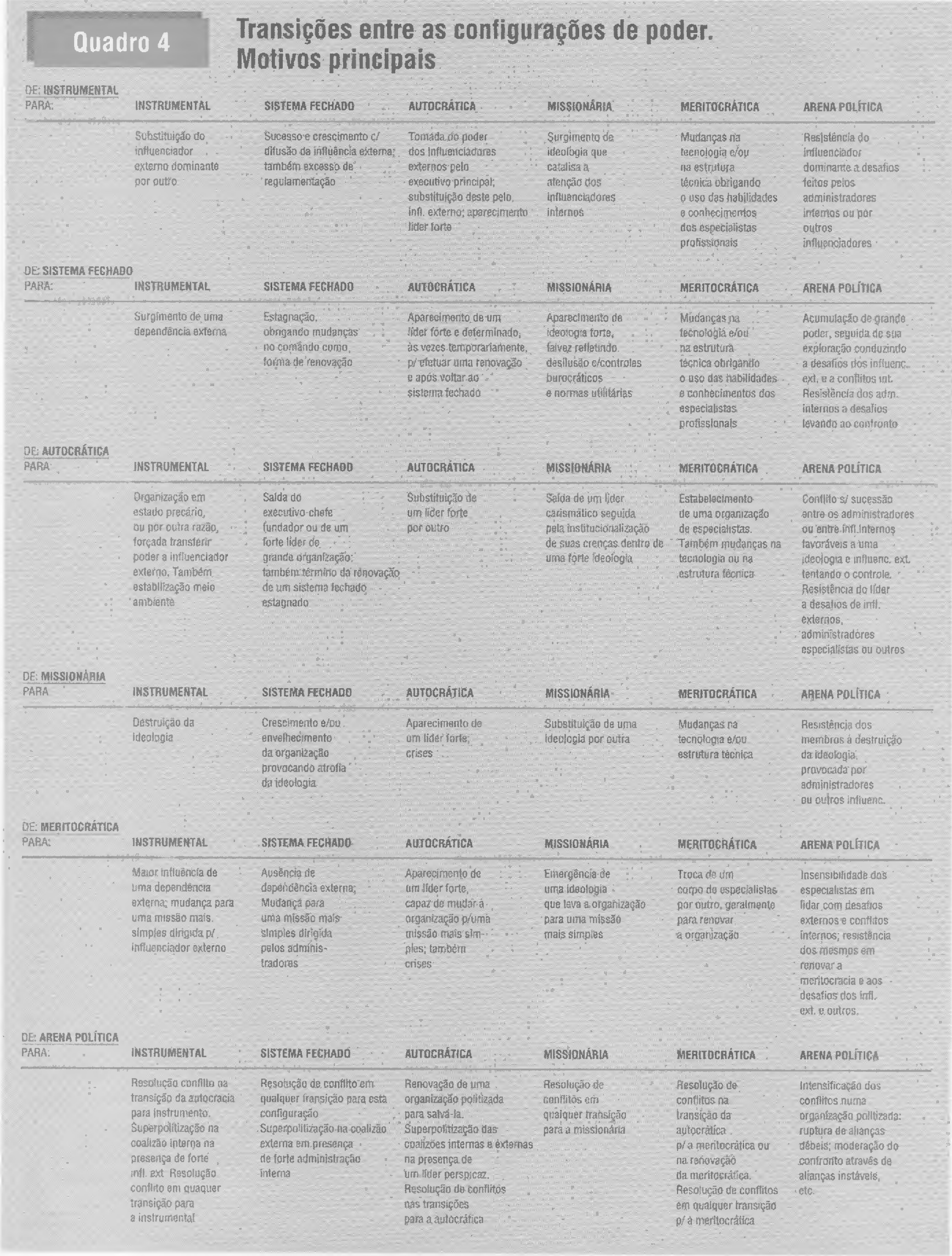


ser mais leais às suas associações profissionais, visto que a socialização é parte básica de suas formações profissionais.

A condição básica para a existência deste tipo de configuração é a existência de uma estrutura operacional tecnicamente complexa, ou a necessidade de lidar com tecnologias também complexas, exigindo assim profissionais com alto nível de especialização.

\section{6- Organização arena política}

A característica básica desta configuração é o conflito, tanto na coalizão externa, que é dividida, quanto na interna, que é politizada.

Pressōes conflitivas, normalmente, são impostas de fora da organização e os jogos políticos são então disputados internamente. Na melhor das hipóteses, a organizaçāo é dirigida visando a atender um grande número de restrições ou metas pessoais; na pior, suas energias são despendidas em jogos e negociações políticas.

Algumas vezes, em não havendo um foco natural do poder, o conflito flui naturalmente; outras vezes, existem duas ou mais concentrações de poder incompativeis entre si, resultando em conflito entre as coalizōes interna e externa, ou mesmo interiormente a cada uma delas.

Apesar de aparecer como disfuncional, esta configuração não é necessariamente uma aberração, pois funciona como um meio necessário na transição de uma para outra configuração natural.

Seu aparecimento se dá quando a organização experimenta um desafio à configuração do poder existente, conflitos entre seus influenciadores dominantes, ou ainda, quando existem forças de poder equivalentes, mas irreconciliáveis na organização.

\section{CARACTERÍSTICAS GERAIS E MOTIVOS PRINCIPAIS DAS TRANSIÇÕES DAS CONFIGURAÇÕES NATURAIS}

O quadro 3 (pg. 13) é disposto de forma a sintetizar, de forma comparativa, algumas das características principais das configuraçōes de poder organizacional, de que trata a teoria.

Já o quadro 4 (pg. 14) resume as principais causas que geram as transiçōes entre aquelas configurações naturais, consolidando assim uma estrutura referencial teórica.

\section{CONCLUSÃO}

Obviamente, no mundo real, nenhuma organização será exatamente idêntica a esses "tipos genuínos" teóricos, visto que

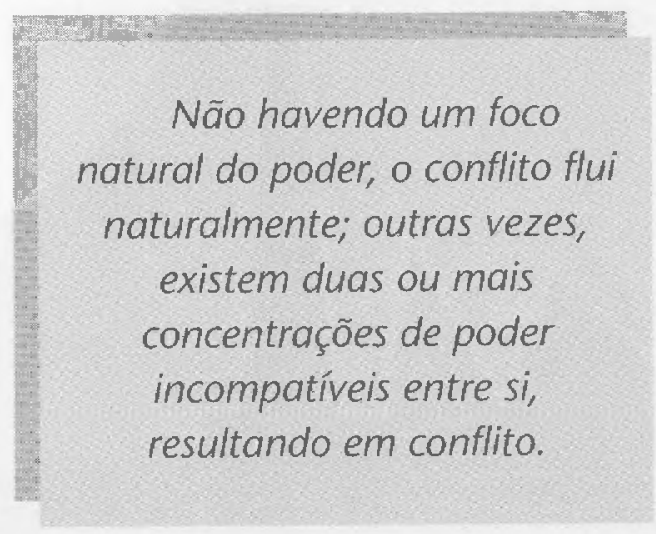

suas criações tiveram como objetivo básico facilitar a dedução de tendências, sendo pois oferecidos como uma estrutura de referência.

Fica claro o intento do autor em deduzir uma teoria descritiva e sistemática que possa crescer, de forma indutiva, com base em dados observáveis no mundo real, na direção de um paradigma.

Por outro lado, não escapa, ao observador mais atento, a tendência prescritiva que emana dessa teoria, o que o autor não nega.

É crença de Mintzberg que prescrever faz parte do trabalho do profissional, para que se possa achar melhores enfoques na execução de políticas. Em outras palavras, ele acredita que a melhor prescrição vem da aplicação de conhecimentos conceituais sobre um fenômeno, dentro de um contexto específico e conhecido, destacando que uma boa teoria descritiva, nas mãos certas, é um instrumento prescritivo, talvez o melhor de todos.

Nessa linha, é importante destacar nesta conclusão, que se estas idéias não forem tomadas como visão do mundo, e assim mantidas no status de estrutura referencial teórica, então, sim, poderão contribuir em alto grau para o entendimento de questões relativas ao poder que permeiam as organizaçōes. ${ }^{10} \square$
10. Sinceros agradecimentos ao Prof. Dr. Carlos Osmar Bertero da EAESP/ FGV pelas orientaçōes. 